$11-2005$

\title{
Crafting Qualitative Research Articles on Marriages and Families
}

Sarah H. Matthews

Cleveland State University, s.matthews@csuohio.edu

Follow this and additional works at: https://engagedscholarship.csuohio.edu/clsoc_crim_facpub

Part of the Family, Life Course, and Society Commons

How does access to this work benefit you? Let us know!

\section{Original Citation}

Matthews, S. H. (2005). Crafting qualitative research articles on marriages and families. Journal Of Marriage \& Family, 67(4), 799-808. doi:10.1111/j.1741-3737.2005.00176.x

\section{Repository Citation}

Matthews, Sarah H., "Crafting Qualitative Research Articles on Marriages and Families" (2005). Sociology \& Criminology Faculty Publications. 39.

https://engagedscholarship.csuohio.edu/clsoc_crim_facpub/39

This Article is brought to you for free and open access by the Sociology \& Criminology Department at EngagedScholarship@CSU. It has been accepted for inclusion in Sociology \& Criminology Faculty Publications by an authorized administrator of EngagedScholarship@CSU. For more information, please contact library.es@csuohio.edu. 


\section{Crafting Qualitative Research Articles}

\section{on Marriages and Families}

This paper aims to assist those who do qualitative research in the field of marriage and family to reduce the number of rejections received in response to article submissions. Recurring shortcomings identified by reviewers and suggestions made to authors about revising papers are organized using headings traditionally used in a research article-introduction and literature review, method, results, and discussion. Considerations stemming from the fact that data on marriages and families are produced largely through interviews also are addressed.

Although there is a vast and growing literature on why and how to do qualitative research, in most research guides production of the research report is the topic that gets the shortest shrift. Furthermore, most advice is general rather than aimed specifically at how to produce journal articles. This paper is intended to provide pointers on crafting refereed articles as the form of the report. An earlier paper published in $J M F$ "was written for scholars who do not engage in qualitative research and/or who are not familiar with its methods and epistemologies" (Ambert, Adler, Adler, \& Detzner, 1995, p. 879). One of its purposes was to educate quantitative researchers who are asked to review qualitative articles. In contrast, this paper is directed at those who do qualitative research and plan to publish in scholarly family journals. The audience, then, is those who use qualitative research

$\overline{\text { Department }}$ of Sociology, Cleveland State University, Cleveland, OH 44115 (s.matthews@csuohio.edu).

Key Words: qualitative research, research report. methods and want to reduce the number of "revise and resubmits," if not outright rejections, they receive in response to journal submissions. The suggestions are likely to be of more use to novices than to the well published, but they may help even seasoned writers recognize practices and strategies that they use without much thought. Although not the intended audience, reviewers may find the issues addressed herein useful as well.

For this paper I rely primarily on my experience as a reviewer and author of qualitative papers that were submitted to various journals over the past 25 years. I concentrate on recurring problems and suggestions for revising papers that the other reviewers and I routinely made to authors. I also draw on reviews of my papers over the same period. Had I had the foresight to keep all the reviews I have read and written, I could claim that this paper is an inductive analysis of them. By drawing on my experiences and the recent reviews that I do have, the paper is as close as I can come to such an analysis. Important to note is that I am a sociologist trained in the symbolic interactionist tradition (Denzin, 1989; Emerson, 2001; Lofland \& Lofland, 1995). As with any qualitative research project, the "findings" presented here are dependent on the analyst, but I am reasonably confident that other reviewers would identify at least some of the same issues, although their emphases undoubtedly would be different.

There is widespread agreement that it is difficult to get qualitative research published in "mainstream" journals. In part, this is because reviewers who are not qualitative researchers often lack the requisite knowledge to provide 
cogent advice about what revisions might make a paper acceptable (Ambert et al., 1995). One solution to this problem is to submit papers that raise as few doubts or red flags as possible. If papers submitted by qualitative researchers, however provocative, are well crafted, reviewers can focus more easily on specific issues that trouble them. Such papers are at least somewhat more likely to be accepted. Admittedly, this is a more pragmatic than political solution, although I am not convinced that the two are necessarily mutually exclusive.

This paper, then, is not about how to do qualitative research. There are many guides available, both single-authored texts and edited volumes. Instead, my assumption is that authors have collected qualitative data, coded it and written memos, and reached the point in analysis to make an argument using a framework grounded in the data. Regardless of how the data were generated-participant observation, qualitative interviews, focus groups, case studies, or written texts - the researcher is now ready to turn the results of analysis into a paper submission to a journal such as $J M F$. What to put in a journal submission and where to put it are the issues addressed in this paper. The advice contained herein may be useful at earlier stages of the research process: The proposed audience for a paper should always be in the writer's mind.

To organize my presentation, I use the standard headings of a research article-introduction and literature review, method, results, and discussion. Because the quality of data is an issue that also requires attention, before moving to the standard headings I first discuss the typical way in which qualitative data about marriage and family are produced. Although this seems to negate my assertion that this is not a paper about how to do qualitative research, understanding the nature of qualitative data collected through interviews is critical to their effective use in a written report. Throughout the paper, I use reviewer and reader interchangeably.

\section{RELYING ON INTERVIEWS}

Qualitative analysis entails making sense of words, those elicited during interviews (whether with individuals or in focus groups), those recorded in fieldnotes during and after episodes of participant observation, or both. Words may also come from written texts. The hallmark of qualitative research data is that those who are studied produce them. Researchers ask questions not to elicit answers to specific questions but to make it possible for social actors to tell about something in their own words. Words are not put into people's mouths, as is the case with fixed-choice questions. Instead, the research subjects are treated as informants; the researcher's goal in an interview is to see a slice of the social world from the informant's perspective. Collecting good data requires that the researcher successfully elicit information that makes it possible to see the world through informants' eyes.

Data collection techniques that produce words rather than numbers are necessary but not sufficient for conducting qualitative analysis. The quality of a research report depends on the data. Although it is possible to write a bad paper with good data, the likelihood of writing a good paper with bad data is low. Some data are so inherently weak that they cannot be subjected successfully to qualitative analysis, but as common are data that may be more than adequate for some purposes but ill suited for what the researcher asks of them. They simply may not include what is needed to make the chosen argument because an author attempts to impose a framework rather than grounding it in the data. Here I focus on what constitutes adequate data. I address the issue of grounding the framework in the data in a later section.

Denzin (1989) argued that data collected through participant observation are the ideal in qualitative research. This is because to understand fully participants' statements, answers to questions, and behavior, the researcher must have "intimate familiarity" (Lofland \& Lofland, $1995)$ with the social world in which informants act. Even to know what questions to ask requires such knowledge. The researchers' goal is to come as close as possible to putting themselves in the context of those studied. The title of one standard guide to doing qualitative research, Analyzing Social Settings (Lofland \& Lofland; Lofland, Snow, Anderson, \& Lofland, 2005), is a reminder that what people do and say occurs within a social context. Accurate interpretation of behavior and words requires knowledge of that context. Although formal and informal interviews are an important part of a set of fieldnotes (Emerson, Fretz, \& Shaw, 1995), the participant observer draws on much more than interviews during analysis. Firsthand knowledge 
of the context allows the researcher to interpret informants' words and actions with confidence. Qualitative interviews, then, take as their model not questionnaires but participant observation.

Marriage and family life, because it occurs "behind closed doors," rarely is open to participant observers. Furthermore, the social settings in which both marriage and family life transpire are dispersed geographically and occur roundthe-clock. Ties are important to understanding behavior even when family members are not in one another's presence. As a consequence, marriages and families are examples of social situations that may be "directly apprehensible only through intensive interviewing. Therefore, rather than being a poor substitute for participant observation, intensive interviewing is frequently the method of choice" (Lofland \& Lofland, 1995, p. 19). Although Hochschild's (1989) classic study of The Second Shift and recent work by Lareau (2000, 2003) on Unequal Childhoods admirably demonstrate that collecting data as a participant observer of marriages and families is possible, few researchers have the luxury or the will to invest such significant amounts of time. In addition, many research questions cannot be addressed through intense involvement with a small number of couples or families.

Those who do research on marriages and families, then, typically choose to do interviews. Important to remember, however, is that an interview should be as much like participant observation as possible. To label the interaction an interview, which implies simply recording answers to questions, is misleading if not a misnomer. Qualitative researchers who offer advice about interviewing are sensitive to this. They often modify or use other words to describe collecting data through face-to-face interaction with an informant, for example, "intensive interview" and "interview guide" (Lofland \& Lofland, 1995), "semistructured interview" (Hermanowicz, 2002), "long interview" (McCracken, 1988), "active interview" (Holstein \& Gubrium, 1995), and "research partnership" (Weiss, 1994). Those collecting qualitative data on marriages and families, then, would do well to think of the interaction not as an interview but as an episode of participant observation. Essentially, the interviewer's role is to encourage the informant to create fieldnotes about the research topic that record the world through the informant's eyes (Weiss).

What does it mean to conduct an interview as if it were participant observation? All guides to doing qualitative interviews stress both asking questions in such a way that one-word answers are not an option and avoiding putting words in informants' mouths. Not as obvious is the importance of asking informants to tell about specific incidents rather than how they felt or feel about something in general. In the course of describing something that happened, informants are also likely to include information about how they felt at the time. The reverse is not the case. Informants do not experience the same pressure to provide details about what happened while telling about how something made them feel. At best, they may choose something from what happened to justify their feelings, in which case the researcher is left with an incomplete picture and words to which meaning must later be assigned cautiously and, for a skeptical reader, often unconvincingly.

As an example, to discover important issues about the division of household labor, it is better to ask what all those involved actually do, to encourage the informant to give full details about the specific tasks and who does them, rather than to begin by asking how the informant feels about the way household labor is divided. In the course of describing the division of household labor, informants will provide details about whether they think the division is fair and why. If the interviewer begins by asking whether the division of labor is fair, the informant is encouraged to start by making a judgment and then to justify it. In the end the researcher is likely to know how the informant feels but not enough about what it is that the informant has feelings about. Describing how informants felt without information about the context that produced the feelings makes for a less than credible report. There is little to draw on to explain feelings or behavior without "intimate familiarity" with the "setting." Analysis has been turned over to the informant.

Another way to illuminate this distinction is to recognize that informants are not social scientists. Their role in the project is not to analyze the data but to provide them. The interviewer's role is to facilitate their providing the data:

When respondents provide generalized accounts, their description expresses a kind of theory or what is most typical or most nearly essential in the class of the event. By doing this, respondents preempt the investigator's task of analysis; it is they who have decided what is important. (Weiss, 1994, p. 73) 
Asking people how they feel about something is to ask them to look at what happened analytically rather than simply to report events. Asking about feelings has a place in the interview, but it is not a substitute for data about the social context that led to the feelings. If a wife is asked about the division of child care in her marriage and family, for example, the initial goal is to obtain as complete a picture as possible of who does what and when for whom. In the course of describing this in detail, she is likely to tell what she appreciates and what she finds difficult or exasperating as well as reveal what she takes for granted. The more she is encouraged to elaborate, the more details about her feelings and her explanation she is likely to include. A complete description provides the researcher with a good picture of the division of child care, but also with information about the conditions under which the division leads to reported feelings and what she believes requires explanation.

In summary, although typically and with good reason those who do research on marriages and families use interviews to collect data, it is important to remain aware that rich data are the crux of good qualitative research. When informants are asked only to answer general questions, analysis cannot go beyond simply reporting what respondents said. Successfully constructing a plausible case in a qualitative article, then, is much more likely if the researcher has collected from members of marriages or families extensive and specific details about the topic.

\section{FOCUSING ON EACH PART OF THE RESEARCH ARTICLE}

To identify and suggest solutions to recurring issues that detract from the presentation of findings in qualitative research articles, I use the standard headings that most journals expect authors to use. Where to place specific suggestions is not straightforward because advice about where not to include something is coupled with advice about where to put it instead. Where requisite components belong is a major difference between qualitative and quantitative articles. Another consideration is that most journals specify a maximum number of pages. For $J M F$ the guideline is 30 , which means that space must be used judiciously. Using space in one section requires forgoing its equivalent in another section.

\section{Introduction and Literature Review}

Researchers choose to do qualitative research on a particular topic for many reasons. Some are highly personal, whereas others stem from a review of a literature that reveals a gap that might be filled with a well designed qualitative study. Whatever the reason, reviewing the literature is an important part of any research project, in most cases the first step. In part this is to avoid reinventing the wheel. Reviewers are likely to be very familiar with whatever wheel is the focus of an article. A charge that the paper adds no new knowledge can only be dodged if the author is also familiar with the literature. Whether writing a thesis or dissertation prospectus, a grant proposal, or simply organizing one's thoughts, tracking down, reading, and synthesizing relevant literature is a critical first step to justify a new research project. For qualitative research, however, this initial literature review is likely to be only one of several and it may never be included in a paper submitted to a journal.

With fixed-choice questions, researchers know in advance what the responses will be; the unknown is the distribution of the responses among the possible choices. The review of a research literature generates hypotheses that organize the analysis and the presentation of findings. In a qualitative interview, what informants will say cannot be known in advance. The ideas that the researcher has prior to entering the field, at least some of which have been gleaned from previous research on the topic, are reflected in the content of the interview guide. The actual interview, however, is likely to take the researcher in unanticipated directions. Part of the process of doing qualitative research, then, is to mine additional research literatures as new ideas are sparked during analysis. Often this means that when the time comes to write the journal article, the literature review that was used to justify the original proposal may be only marginally relevant.

A recurring mistake, then, is to use the initial literature review in the journal submission rather than to draw only on literature directly related to the research question addressed in the paper. Especially if authors have invested a great deal of time in reviewing the literature before designing the study, they may find it difficult to forgo putting the carefully constructed literature review in the paper. To focus the reader's 
attention on the results of the analysis presented in the paper, however, it is important not to succumb to the temptation. The "life history" of the research report is not of interest to readers nor is it likely to direct their attention to the specific findings presented in the paper. Furthermore, space used to review a largely irrelevant literature can be put to better use in other sections of the paper.

The introduction and review of the literature in a qualitative article typically is relatively short. Unlike a paper that begins by reviewing a body of literature to justify hypotheses, reference to the research literature at the beginning of a qualitative paper is intended solely to make the case that this is an area of research that is important to pursue with the qualitative research design that generated the data analyzed for the paper. Only after the reader is familiar with the findings does a discussion of how they are related to previous research make sense. In a qualitative article, then, the research literature is primarily relevant in the discussion section.

\section{Method Section}

Regardless of research design, the goal of the method section of an article is to provide the reader with enough information to replicate the study. Too often, qualitative researchers devote space to defending the method instead of using it to provide enough details to give readers a complete picture of how the data were collected and analyzed. A long epistemological discussion of the validity of qualitative research is not likely to be helpful, although a brief one will let readers know the author's theoretical bent. The argument that employing a qualitative research design will get at the issues the researcher wishes to address already has been made in the introduction. The method section conveys important pieces of information to readers so that they can evaluate the argument made by the author.

Who are these informants? Readers need to know how the informants were selected, not only through what venues but also by what recruitment pitch. Specifically, what were informants told about the study when they volunteered or were selected to participate? For research on the division of labor in adult sibling groups, for example, pairs of sisters with parents aged 75 or older were recruited through local and campus newspapers to participate in research on older families (Matthews \& Rosner, 1988). Had the project been billed as a caregiving study, a different group of informants would have volunteered, specifically, those who identified themselves as caregivers. Instead, only some of the sisters who volunteered to participate labeled themselves in this way. Furthermore, specifying pairs of sisters meant that those who were not speaking to one another were unlikely to volunteer. This was important to remember when interpreting the findings, particularly when considering to whom they might apply. As another example, if informants were recruited through family support groups, for instance, grandparents who have lost access to their grandchildren, the fact that these informants were distressed enough to join a support group and also saw such groups as useful is important for the reader to know. Not all such distressed grandparents join groups, and losing contact with grandchildren may not distress all grandparents. Also critical for the evaluation of qualitative data is that informants recruited through groups have interacted with one another and read the same literature. Similarities among their perspectives are very likely to result from a "party line."

There is nothing inherently wrong with most methods of recruiting informants, but being clear about how informants were selected provides the reader with critical information with which to evaluate the findings. Qualifications to findings often stem from the characteristics of the participants, which in turn are related to how they were recruited. Limitations should be spelled out clearly, not glossed over. To whom the specific informants' experiences might be generalizable is important to address in the discussion section of the paper. When authors make clear that they have thought carefully about the limitations imposed by a specific recruitment strategy, the reader is more likely to be convinced by the argument presented in the paper. This is not only because to whom the findings might apply is spelled out but also because it provides evidence that the author is not naively assuming that, to continue using the previous example, the grandparents included in the study are representative of all grandparents who lose contact with their grandchildren. When authors point to qualifications, it indicates that they are well aware of potential limitations to the generalizability of the findings. This enhances their credibility and, by implication, that of the 
reported findings. It also removes one obvious objection from a reviewer's arsenal.

Research instrument. More detail should be included about the research instrument than that it comprised open-ended questions. The reader will learn what interviewers and informants said from the data included in the results section of the paper. In the method section the reader needs information about the topic areas covered in the interview, especially about the portion that was most important to the paper. What were the general parameters under which the data, broadly and more specifically, were produced? Articles based in qualitative data often draw on a portion of a research project. In order to make judgments about the author's assertions, readers may need some information about the larger study but primarily they need to know about the portion that informed the paper at hand. Unlike a survey research instrument, from which specific questions can be identified, it may not be possible to produce exact questions from a qualitative interview both because interviews are more free-floating and because there is little space. Nevertheless, in order to evaluate the credibility of the report, the reader needs to know what elicited the informants' words. This is also the place to add any details about interviewers or researchers that pertain to the production of the data, for example, that interviewers are of the same age, gender, or race as the informants or that the researcher has firsthand knowledge of their situation.

Analysis. Much is written about how to analyze qualitative data. Most agree that it is a creative process that requires spending a great deal of time with the data, reading and rereading, coding and recoding, writing memos and rewriting memos and then making connections among them, until an argument emerges that is grounded in the data. How to put this into words in the method section of a paper is problematic. A short description of analysis is enough when it is buttressed by the rest of the method section that provides evidence that the author recognized and included the components of a good qualitative study. As long as the study has been well designed, the analysis section can be fairly brief. The proof of the quality of the analysis lies in the results section of the paper. An overly detailed description of the analysis process is unlikely to convince the reader and robs pages from the results section. Detailed description of how the analysis was accomplished is a luxury of a monograph that simply is not available in an article.

Describing the informants. In addition to how many people were interviewed and the length of the interviews, the method section includes demographic and other relevant information about the informants. Armed with this information, it is possible for the reader eventually to entertain alternative explanations for the findings, for example, to ask, "Are the findings related to the fact that all of the informants have very young children? Would the experiences of parents with older children be different?" Providing readers with enough detail to allow them to entertain alternative explanations is a good thing, not something to guard against. Research findings should lead readers to new understandings of a phenomenon, but also to questions that will spark future research. Which characteristics of the informants to include depends in part on the findings. Standard demographic variables may suffice, but if there are other characteristics that distinguish informants from one another or a larger population, they should be reported here as well.

Informants for research that uses qualitative methods rarely are a random sample of a known population. Some authors try to make the case that their informants are a sample by comparing demographic characteristics of their informants to a population and then claiming little difference. This not only wastes space but, more important, is misleading. Even if the match is good, unless the informants were selected randomly, the case that they are representative cannot be made. Any suggestion that it can be is likely to annoy reviewers. Furthermore, recognition that generalization to a population is not a goal forces the researcher to think more carefully about what generalizations might be possible to make in the discussion section of the paper. This issue is not unrelated to recognizing the limitations imposed by the manner in which informants were recruited for the study.

\section{Results Section}

As already noted, I am not making suggestions about how to do the analysis. There are many books to consult on how to do qualitative data analysis (e.g., Becker, 1998; Emerson et al., 1995; Lofland \& Lofland, 1995; Weiss, 1994). Reading a variety of them not only before but 
during analysis to look for other ways to approach the data is useful. It also is helpful to read qualitative articles in a journal to which the paper will be submitted with an eye to discovering how they were constructed and what about them is worth emulating. In this section, however, I assume that authors have analyzed the data and decided, more or less, what argument they want to make. I write "more or less" because often it is in the process of writing that an author discovers the logic of an argument (Becker, 1986).

The heart of the paper is the presentation of the results of the analysis using a framework that is grounded in the data. In the results section the author presents an argument drawn from analysis of the data and provides evidence to support it. It should begin early enough in the paper to leave ample room not only for it but also for the discussion section. It is very helpful to the reader if the author presents a concise, introductory paragraph to serve as a guide to the case that follows.

A framework that is not grounded in the data, that is not inductive, is unlikely to be convincing because the requisite evidence to support it will simply not be available. An author may decide, for example, to distinguish among children who have biological siblings, those who have stepsiblings, and those who have half-siblings, and to begin by presenting excerpts from interviews for each type. If the author then suggests that there is no difference between two of the types, for example, step- and half-siblings, readers may question with good reason why the author asked them to read about the distinction. The initial research design may have included equal numbers of each type, but analysis of the data may indicate that the distinction was unimportant. The analyst must be willing to let go of distinctions that initially were thought to be important even if they were built into the research design (and, as noted above, the original literature review that argued that the distinction is important), and to look in the data for what distinguishes siblings from one another. From here the author may ask what led to the differences or what the consequences are. Important here is that the elements of the paper are connected, that an argument is made. Simply illustrating someone else's concepts with the data is rarely illuminating enough to satisfy reviewers.

How much data to include? The reader needs to be convinced that authors have interpreted correctly or at least credibly what they have been told by informants or texts. This requires that evidence be included to support each of the author's assertions. Note that I use the word evidence rather than examples. This is an important distinction. The author may choose one from a host of similar excerpts to include in the paper, making it seem like an example, but excerpts are data. Use of the word example suggests to the reader that the evidence presented is merely anecdotal.

There is no specific rule for how much data to include in the paper, but the results section should be at least half of the paper. Some authors err on the side of presenting only their conclusions without providing sufficient evidence. In essence, they ask the reader simply to trust that their interpretations are correct. Teams of qualitative researchers seem more likely to do this. So much effort has gone into making sure that everyone agrees, that making this case takes space that would be used better in the results section. How the consensus was reached is not as important as providing evidence to support the consensus.

Other authors include so much data that the reader is distracted from the argument being made, becomes bored, or both. This can occur because too many excerpts are used or those that are chosen are not well edited. Because the subject of the study presumably is inherently interesting to the author, reading copious details is not considered a waste of time. Readers, however, are likely to be impatient if asked to read long excerpts from an interview transcript, even if they are well edited. This is one of the major differences between presenting results in an article rather than a monograph. Someone reading a book expects to read details. Someone reading a journal article has very different expectations. Rather than presenting long excerpts, then, it is preferable to include short ones that are to the point, and to weave back and forth between assertions and evidence throughout the text.

Data drawn from interview transcripts should be carefully edited. Presenting extraneous information in an excerpt leads the reader down tangents that distract from the author's reason for including it. The main point the author wishes to make is likely to be lost. In early drafts of the paper, including too much of an excerpt is a good idea, but as the draft moves ever closer to a version that will be submitted to a journal, with each revision, the data excerpts should be 
as carefully edited as the rest of the text. Often this means omitting sentences and phrases to which the author is particularly attached, but including extraneous information in data excerpts encourages the reader to focus on something that is not central to an author's argument.

Avoid "explaining" data excerpts. Carefully choosing and editing appropriate excerpts from interviews makes it unnecessary to repeat in the text what an informant was just quoted as saying. The author's stance should be, "This is what I concluded from the data that were categorized in this way," followed by one or two excerpts to provide supporting evidence. If authors feel compelled to explain to readers in great detail what was just quoted, they may not have sufficiently honed the point that the data excerpt was intended to make. The reason for including the excerpt should be immediately apparent to the reader. Rewriting the preceding text is preferable to lengthy explanations of its meaning in subsequent text.

Focus exclusively on the data in the results section. The purpose of the results section is to convey to readers what the study found. Although in some cases it is appropriate to refer to others' findings or ideas, citing the results of others' research in the findings section tends to confuse readers who must keep track of which findings are the author's and which are someone else's. The more appropriate place to cite the research literature is in the discussion section where the author indicates how the findings from this study add to existing or challenge previous findings.

When constructing the results section, authors should put on blinders in order to focus on their own data. If the study is about the relationship between 20 impoverished children and their mothers, for example, what others have reported about other poor children and mothers is irrelevant. Rather, the author's goal in this section of the paper is to tell the reader about the relationships between these 20 children and their mothers. What others have concluded about parent-child relationships or about poverty should fade into the background while the author lays out clearly the findings derived from data produced by these informants. Reference to the existing research literature belongs in the discussion section. What is important in the results section is the author's interpretation of what these informants said about the issues at hand. In my experience, this is one of the most difficult obstacles for authors to surmount; that is, to focus on making the argument or elucidating a framework exclusively with the data collected for the study.

One trick I use to keep my attention focused on the actual data is to write in the past tense. Although the following two sentences are very similar, the first conveys that wives in general are critical, the second that wives included in the study were critical.

\section{S1: Wives are critical of husbands who do not do their share of the housework. \\ S2: The wives criticized their husbands for not doing their share of the housework.}

It is much easier for a reviewer to doubt the veracity of the first statement, much more difficult to doubt the second because it makes clear that the assertion is based on data provided by wives included in the study. Writing in the past tense focuses the author on the actual data and keeps in check the temptation to generalize inappropriately. Did all the wives in the study criticize husbands for not sharing? Were there some wives, even one, who were not critical? What was different about their situation? Not wives in general, but the experiences of these particular wives belong in the results section of the paper.

Truth from someone's perspective. As noted earlier, most research on marriages and families relies on interviews. It is unusual for both partners to be interviewed in research on marriages just as it is atypical for more than one member to be included in research on families. Informants tell about relationships and situations from their perspectives. It is important to remember that those about whom they are speaking, if given the opportunity, might provide very different versions. Writing in a way that conveys that the data are someone's perspective is likely to make a reader less skeptical.

Furthermore, the assertions made by informants cannot be treated as truth. An informant, for example, may report that he was unfairly treated by his parents. This is not the same as his actually being treated unfairly by his parents. This distinction is important, especially when analysts are tempted to make causal statements. An informant may explain current marital problems by referring to something that 
happened to her in childhood. That does not mean that there is a connection but only that she believes there is one. A legitimate question to ask is why the informant believes this. Authors who make clear that they understand that they are not reporting facts per se but someone's interpretation of them increase their credibility.

\section{Discussion Section}

The discussion section begins with a brief summary of the findings, one or two paragraphs, followed by text in which connections are made between the findings and the research literature. No new data should be introduced in the discussion section. If new data seem necessary, the results section is probably incomplete. Here the author should be very explicit about the ways in which the findings reported in the paper add to, challenge, or clarify what has been reported in previous studies. The discussion section is where the research literature deemed relevant by the analytic framework is featured. Which literature the study informs is an important decision. As noted earlier, it may be quite different from the one that spawned the study. Results of qualitative studies are often useful in explaining findings reported in quantitative studies where authors must speculate about why variables are related to one another. Important questions include the following: Are these findings consistent with or contradictory to earlier findings? Do they clarify seemingly conflicting findings? Are they consistent with the results of other qualitative studies on the topic? Answers to these questions situate the findings within a broader research literature.

The typical mistakes in a discussion section are not to write enough or to write about something that is not clearly connected to the findings. Some authors write very little, perhaps because they believe that the findings are intrinsically interesting and that their significance is obvious. The reader, however, requires much more instruction. What may seem obvious to the author must be spelled out for the reader. Other authors may attempt to relate the findings to an issue that the data cannot directly inform. The author's case may be legitimate, but not one that follows logically from the findings presented in the paper. The study may have been undertaken, for example, because the author sees some injustice in the way marriages and families are organized. The motivation for the study, however, may be only tangentially related to the findings. I am not suggesting that making a connection between findings and a larger issue is never possible, only that there should be evidence of a relationship between the two. Readers will be tempted to dismiss the paper if the discussion section seems to have little connection to the findings. Simply asserting that there is a connection is not convincing.

Toward the end of the discussion section, limitations of the study are delineated. This does not mean pointing out that because all the informants are of one race, gender, social class, or age, the findings may not apply to everyone. Instead, the focus is on such things as how the informants were selected. What biases were introduced by this selection process? To whom might these findings not apply as a result of the way informants were recruited? What questions were raised in analysis that could not be addressed because a category of informants was not included or because informants were not asked to talk about a topic that now seems important? This is an opportunity for the author to suggest research areas that build on the study and clarify its findings. This is a place to demonstrate to the reader that much thought has gone into interpreting these data and that these findings contribute to a research literature.

\section{IN CONCLUSION}

Primarily by identifying pitfalls that recur in research papers submitted to journals, suggestions have been made about what to consider when crafting a qualitative article in the field of marriage and family. Regrettably, I cannot claim that the points made are the result of a qualitative analysis of reviews. As I indicated in the introduction, discovering and making explicit how various types of qualitative research reports are crafted has received little attention. To my knowledge, there are no inductive analyses of reviews of journal submissions, whether quantitative or qualitative. Empirical research on this issue might make the process more transparent and perhaps reveal that beliefs about the review process and its relationship to what is published are at least partially erroneous. Nevertheless, this paper is based on reviewing papers for journals, reading other reviewers' reactions to the same papers, and digesting reviews of my own papers over more than two decades. The issues identified in this paper are ones that I judge to be persistent problems. 
In this paper I chose to be pragmatic rather than political by conforming to conventions rather than challenging them. By organizing my suggestions following the traditional outline of a research article, I have purposely suggested that presenting a qualitative research report is not that different from presenting a quantitative one. Both quantitative and qualitative research use the scientific method to collect and analyze data in order to build on an existing body of knowledge.

In my role as a referee for articles submitted to journals, my suggestions have been specific, intended solely to improve the paper at hand. For this paper I was required to give general advice and I did so with some trepidation. I am acutely aware that there is no formula for crafting a qualitative research article. The suggestions made here surely do not apply in all cases. Examination of the articles I have published would undoubtedly reveal that I have not followed my own advice. Other qualitative researchers undoubtedly would have chosen to focus on different issues. I do not offer these suggestions, then, as "written in stone," that is, as the only right way to construct a qualitative research article in the field of marriage and family. Instead, they are intended as guidelines that may be as useful when they are consciously challenged as they are when followed.

\section{REFERENCES}

Ambert, A.-M., Adler, P. A., Adler, P., \& Detzner, D. F. (1995). Understanding and evaluating qualitative research. Journal of Marriage and the Family, 57, 879-893.

Becker, H. S. (1986). Writing for social scientists: How to start and finish your thesis, book, or article. Chicago: University of Chicago Press.
Becker, H. S. (1998). Tricks of the trade: How to think about your research while you're doing it. Chicago: University of Chicago Press.

Denzin, N. (1989). The research act. Englewood Cliffs, NJ: Prentice-Hall.

Emerson, R. M. (2001). Contemporary field research: Perspectives and formulations. Prospect Heights, IL: Waveland.

Emerson, R. M., Fretz, R. I., \& Shaw, L. L. (1995). Writing ethnographic fieldnotes. Chicago: University of Chicago Press.

Hermanowicz, J. S. (2002). The great interview: 25 strategies for studying people in bed. Qualitative Sociology, 25, 479-499.

Hochschild, A. R. (1989). The second shift. New York: First Avon Books.

Holstein, J. A., \& Gubrium, J. (1995). The active interview. Thousand Oaks, CA: Sage.

Lareau, A. (2000). My wife can tell me who I know: Methodological and conceptual problems in studying fathers. Qualitative Sociology, 23, 407-433.

Lareau, A. (2003). Unequal childhoods. Berkeley: University of California Press.

Lofland, J., \& Lofland, L. H. (1995). Analyzing social settings: A guide to qualitative observations and analysis (3rd ed.). Belmont, CA: Wadsworth.

Lofland, J., Snow, D. A., Anderson, L., \& Lofland, L. H. (2005). Analyzing social settings: A guide to qualitative observations and analysis (4th ed.). Belmont, CA: Wadsworth.

Matthews, S. H., \& Rosner, T. T. (1988). Shared filial responsibility: The family as the primary caregiver. Journal of Marriage and the Family, 50, 185-195.

McCracken, G. (1988). The long interview. Newbury Park, CA: Sage.

Weiss, R. (1994). Learning from strangers: The art and method of qualitative interview studies. New York: Free Press. 